\title{
28 Research Square \\ Incidence of COVID-19 among people living with HIV in Southern Spain
}

\author{
Marta Fernandez-Fuertes \\ Hospital Universitario de Valme \\ Elena Rodriguez-Pineda \\ Hospital Universitario de Valme \\ Ana Fuentes-Lopez \\ Hospital Universitario San Cecilio \\ Anaïs Corma-Gomez \\ Hospital Universitario de Valme \\ Pilar Rincon \\ Hospital Universitario de Valme \\ Esther Serrano-Conde \\ Hospital Universitario San Cecilio \\ Luis M Real \\ Hospital Universitario de Valme \\ Federico Garcia \\ Hospital Universitario San Cecilio \\ Juan Macias \\ Hospital Universitario de Valme \\ Juan A Pineda ( $\square$ japineda@telefonica.net) \\ Hospital Universitario de Valme
}

\section{Research Article}

Keywords: COVID-19, HIV, SARS-CoV-2 infection, serum antibodies, antiretroviral therapy

Posted Date: November 17th, 2020

DOI: https://doi.org/10.21203/rs.3.rs-110312/v1

License: (c) (i) This work is licensed under a Creative Commons Attribution 4.0 International License. Read Full License 


\section{Abstract}

Objective and Design: The incidence of SARS-CoV-2 infection among people living with HIV (PLWH) has been estimated on the basis of reported symptomatic clinical cases. However, as asymptomatic cases are common and there have been limitations of health care systems for COVID-19 microbiological diagnosis, these estimations may be misleading. The availability of reliable serology for the diagnosis of COVID-19 may overcome this drawback. This study was carried out in order to reveal the actual incidence of SARS-CoV-2 infection in PLWH in Southern Spain.

Methods: This is a prospective cohort study including HIV infected patients from the Unit of Infectious Diseases of a university hospital in Seville, Southern Spain. Patients were enrolled in the study if 1) they had attended the outpatient clinic from September $1^{\text {st }}$ to December $31^{\text {st }}, 2019$ (baseline), and 2) had a subsequent evaluation from March $1^{\text {st }}$ to June $30^{\text {th }}, 2020$ (intra-pandemic). Serum antibodies against SARS-CoV-2 were determined in baseline and intra-pandemic samples.

Results: 326 patients were included in the study. Of them, 4 (1.25\% [95\% Cl: 0.3\%-3.1\%]) developed COVID-19. One patient developed bilateral pneumonia and died. The remaining three showed mild respiratory symptoms suggesting COVID-19. No asymptomatic SARS-CoV2 infection was observed in this study. No patient with COVID-19 was tobacco smoker. The incidence of COVID-19 among non-smokers was $2.5 \%(95 \% \mathrm{Cl}[0.6 \%-6 \%], \mathrm{p}=0.057$ versus smokers).

Conclusions: The incidence of COVID-19 among PLWH in our area was low and similar to that observed in the general population. The frequency of asymptomatic cases might be lower than in patients without HIV infection. Tobacco smoking could be associated to a lower incidence of COVID-19.

\section{Introduction}

SARS-CoV-2 infection pandemic has extensively involved Spain, with over 700.000 confirmed cases by September 2020, and an ongoing severe second wave. The first reported case in our country was diagnosed in February 9th, $2020^{1}$. COVID-19 cases have been observed among people living with HIV (PLWH) in many countries across the world ${ }^{2-9}$. Studies published so far suggest that at least in Europe, China and North America, HIV coinfection does not increase the risk for SARS-CoV-2 infection. However, estimated incidences in most of these studies have been based in reported clinical cases, confirmed by PCR. Consequently, estimations might be misleading, as a substantial part of SARS-CoV-2 infections are asymptomatic ${ }^{10}$ and diagnosis was limited by test shortage and health care system capacity surpassing ${ }^{11}$

Similarly, the impact of HIV coinfection in the outcome of SARS-CoV-2 infection has not been clearly defined. PLWH, due to premature ageing and comorbidities, could be at a higher risk of poor outcomes from COVID-19. However, the results of most studies on this issue have not supported this hypothesis ${ }^{2-9}$. Moreover, a study has suggested that tenofovir diphosphate (TDF) plus emtricitabine (FTC) could prevent severe COVID-19 in PLWH ${ }^{9}$. Conversely, a study from South Africa showed that HIV-coinfection is associated with a doubling of COVID-19 mortality risk ${ }^{8}$. However, again, COVID-19 diagnosis, based in reported clinical cases, is a limitation for these studies, as milder cases, as well as those in which PCR for SARS-CoV-2 was not carried out, could have gone unnoticed. The availability of a reliable serology for the diagnosis SARS-CoV-2 infection ${ }^{12}$, allowing prospective seroincidence studies, where all infections are accurately identified, may overcome the above-mentioned limitations. Because of this, we undertook this study, with the purpose of providing insight on the actual incidence and clinical outcome of SARS-CoV-2 infection in PLWH in Southern Spain during the first wave of COVID-19 pandemic.

\section{Methods}

\section{Study patients}

This is a study conducted in a cohort of prospectively followed PLWH at the Unit of Infectious Diseases of a university hospital in Seville, Southern Spain. All patients from this cohort are seen at least every six months. At each visit, all patients undergo clinical evaluation and blood drawing for routine testing, as well as sample storage for future determinations. After February 2020, all patients were specifically questioned on respiratory or general symptoms suggesting COVID-19 since the former visit. Serum samples from all patients were cryopreserved at $-80^{\circ} \mathrm{C}$ at each visit. Patients enrolled in that cohort were included in the present study if they fulfilled the following criteria: 1) they had attended the outpatient clinic of our Unit from September $1^{\text {st }}$ to December $31^{\text {st }}, 2019 ; 2$ ) had a subsequent evaluation from March $1^{\text {st }}$ to June $30^{\text {th }}, 2020$. 


\section{COVID-19 diagnosis}

A diagnosis of COVID-19 was established if, at least, one of the following criteria were met: 1) SARS-CoV-2 RNA was detected in nasopharynx exudate by PCR; 2) Seroconversion for SARS-CoV-2 antibodies was documented between the baseline (pre-pandemic) and the following (intra-pandemic) sample by two different procedures.

\section{Laboratory procedures}

All samples were tested for serum SARS-CoV-2 antibodies by electro-chemiluminescence immunoassay (ECLIA), which detects total serum

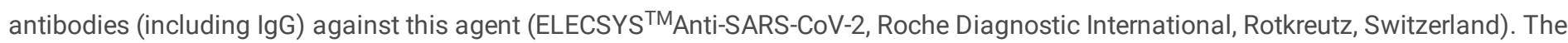
reported sensitivity of this test 14 days after infection is $99.5 \%$ and the specificity for routine diagnostic is $99.8 \%{ }^{13}$. Serum samples that tested positive by this procedure were also analyzed by an enzyme immunoassay (EIA) for IgG and IgM antibodies against SARS-CoV-2 (COVID-19 ELISA ${ }^{\text {TM }}$, Vircell, Granada, Spain). The clinical sensitivity of this test for IgG is $85 \%$ in patients $10-19$ days after a positive PCR and the specificity was $98 \%$ in blood donors in the pre-pandemic period ${ }^{14}$.

Baseline samples showing reactivity for serum SARS-CoV-2 antibodies were retested for IgG against S1 and S2 SARS-CoV-2 spike proteins (specific for this virus) and N3 nucleocapsid proteins (shared with other coronaviruses) by an in-house EIA (Vircell, Granada, Spain). Similarly, reactions against EIA plaque without any antigen coating were also analyzed.

PCR analyses for SARS-CoV-2 RNA detection in naso-pharynx exudate were performed by a commercially available procedure (Cobas SARS-CoV-2 ${ }^{\mathrm{TM}}$ Roche Diagnostic International, Rotkreutz, Switzerland), following the manufacturer instructions.

\section{Statistical analysis}

Continuous variables are expressed as median (Q1-Q3) and categorical variables as numbers (percentage). 95\% confidence interval (95\% $\mathrm{Cl}$ ) is provided for the main incidence rates. Frequencies were compared by the chi-square test or the Fisher's test, when there was at least one cell with an expected frequency lower than 5 . The Mann-Whitney $\mathrm{U}$ test was used for comparing continuous variables.

These analyses were carried out using the SPSS software 25.0 (IBM Corporation, Somers, New York, New York, USA)

\section{Ethical issues}

The study was designed and conducted following the Helsinki declaration. The Ethics committee of the Hospital Universitario de Valme approved the study. All patients gave written informed to be entered in the cohort.

\section{Results}

\section{Features of the study population}

Among the 690 patients included in the overall PLWH cohort, 428 (62\%) subjects attended our outpatient clinic from September to December 2019 , and 326 (76\%) of them had a subsequent visit within the pandemic period. Accordingly, 326 patients were the population finally included in this study. The main baseline features of the analyzed subjects, as well as the antiretroviral drug combinations they were receiving, are shown at table 1 . Only two patients were treated with TDF plus FTC, whereas the remainders receiving tenofovir-including regimens were on tenofovir alafenamide (TAF) plus FTC.

\section{Incidence of SARS-CoV-2 infection}

At the baseline study visit, four (1.25\%) patients turned out to be seroreactive for SARS-CoV-2 antibody by ECLIA. Two of them were seronegative by EIA. The remaining two patients also tested positive for IgG anti-SARS-CoV-2 by EIA. However, in one of them the serum sample was reactive against the EIA plaque uncovered by antigens and the sample taken during the pandemic period yielded a negative result by ECLIA. The fourth sample reacted for specific IgG against N3 SARS-CoV-2 antigen and it did not for IgG against S1 and S2. The same result was obtained in a sample from the latter patient collected at the pandemic period. Consequently, all these four samples were considered as false positive results.

Four patients (1.25\% [95\% Cl: $0.3 \%-3.1 \%)]$ who tested negative for SARS-CoV-2 at baseline developed COVID-19 during the pandemic period (table 2). One patient was admitted because of severe bilateral pneumonia, developed respiratory failure and, eventually, died. No serum sample from the pandemic period was available for antibody testing from this patient but SARS-CoV-2 RNA was detected by PCR in 
nasopharynx exudate during the symptomatic period. The remaining three subjects suffered from low-grade fever and mild respiratory symptoms, which did not require hospitalization and that subsided with symptomatic therapy. In all these three patients, seroconversion for SARS-CoV-2 antibodies was documented. In one these three individuals SARS-CoV-2 RNA was also detected by PCR whereas in the remaining two patients, PCR was not carried out due to health-resource limitations. No further seroconversion was observed.

\section{Factors associated with COVID-19 occurrence}

No association between the following parameters and COVID-19 emergence was observed: age, sex, HIV infection way, alcohol or opiate use, nadir or baseline CD4+ cell counts, HIV viral load, CDC clinical category, HBV or HCV serostatus and Charlson index. Three (4.3\%) subjects who were treated with abacavir (ABC) plus lamivudine (3TC) including combinations, $1(0.6 \%)$ on TDF or TAF/FTC-based regimens, and none receiving 3TC-including dual therapy or nucleos $(\mathrm{t})$ ide free combinations developed COVID-19. The incidence of COVID19 among subjects treated with TDF or TAF/FTC-based regimens tended to be significantly lower than that observed among those receiving ABC/3TC $(p=0.085)$. The analysis of the relationship of COVID-19 with other antiretroviral drugs or drug families did not show any association. Three $(2.7 \%)$ out of 112 who were receiving dolutegravir versus one $(0.5 \%)$ out of $214(p=0.119)$ who were not developed COVID-19. The four patients who presented with a COVID-19 episode were non-smokers. This yields an incidence among non-smokers during the study period of $2.5 \%(95 \% \mathrm{Cl}[0.6 \%-6 \%], \mathrm{p}=0.057$ versus smokers).

\section{Discussion}

The results of this study show that the incidence of COVID-19 among PLWH in Southern Spain during the first wave of the pandemic was low and not different of that found in Spanish patients without HIV infection ${ }^{9}$ and in other cohorts of PLWH ${ }^{15}$. Remarkably, no asymptomatic cases were discovered by antibody testing, and all patients who developed COVID-19 had showed symptoms which led to a diagnosis of suspected, or PCR-confirmed COVID-19.

The incidence of COVID-19 among the general population aged from 20- to 79-year-old during the first wave of the pandemic in Spain was $0,417 \%{ }^{9}$. This figure falls into the $95 \% \mathrm{Cl}$ for COVID-19 incidence found in this study. Among PLWH, the reported incidence of COVID-19 has ranged from $0.2 \%$ to $2.8 \%{ }^{15}$, again not different to that found herein. In ENE-COVID study, a cross-sectional seroepidemiological survey conducted across all Spanish regions from May $18^{\text {th }}$ to June $1^{\text {st }}, 2020^{16,17}$, the prevalence of positive plasma SARS-CoV-2 antibodies by a chemiluminescent assay in a random sample of 1805 Seville province inhabitants was 1.3\%. In 1697 members of this population, the seroprevalence observed from June $8^{\text {th }}$ to June $22^{\text {nd }}, 2020$, was $2.7 \%(95 \% \mathrm{Cl} 1,8 \%-3,9 \%)$ using a point-of-care test ${ }^{17}$. Assuming that the four seroconverters identified in our study were seropositive in the above-stated weeks, the figure observed by us would be not significantly different of those found in this nationwide study.

The estimated proportion of asymptomatic SARS-CoV- 2 infections reported so far has been very variable, ranging from $18 \%$ to $81 \% 10,18$. Specifically, in the seroepidemiological nationwide Spanish ENE-COVID study ${ }^{16,17}$, around one third of patients harboring plasma SARSCoV-2 antibodies did not report any symptom suggesting COVID-19. Therefore, it is noteworthy that no asymptomatic case has been observed in our study. We cannot rule out that some patient who had developed asymptomatic infection at the beginning of the pandemic tested negative for SARS-CoV-2 serology in June, because of plasma antibody vanishing. In fact, plasma antibodies against SARS-CoV-2 have been reported to disappear shortly in a part of asymptomatic patients ${ }^{19}$. However, these results have not been confirmed in other study from Iceland, including a larger number of patients, which showed that antibodies do not decline within 4 months after diagnosis ${ }^{20}$. In any case, data presented herein are in line with the greater clinical severity of this disease among HIV-infected patients suggested by studies conducted in South Africa ${ }^{8}$ or in Italy ${ }^{21}$

Four (1.25\%) patients tested positive for serum SARS-CoV-2 antibodies in the sample collected in the pre-pandemic period by the ECLIA technique used as a first step in this study. Two of them also yielded a positive result by EIA for IgG anti-SARS-CoV-2. A thorough analysis of these samples showed that they were false positive results, due to unspecific reactions against the EIA plaque or because the patient harbored IgG antibodies against N3 antigen, a coronavirus protein not specific for SARS-CoV-2. The proportion of false positive results observed in this study is consistent with that reported by the procedure's manufactures ${ }^{13,14}$. However, we should be aware of the possibility of these reactions when interpreting a positive SARS-CoV-2 antibody test, particularly in patients without symptoms and in low incidence settings.

Surprisingly, a trend to a statically significant association between tobacco smoking and lower incidence of COVID-19 was found in this study. Smoking has been reported to be associated with and increased risk of COVID-19 severity ${ }^{22}$. Tobacco smoke exposure results in inflammatory processes in the lung, increased mucosal inflammation, expression of inflammatory cytokines and tumor necrosis factor a, 
increased permeability in epithelial cells, mucus overproduction, and impaired mucociliary clearance ${ }^{23}$. Moreover, nicotine induces ACE-2 overexpression in human bronchial epithelial cells ${ }^{24}$. All these factors may contribute to a greater severity of COVID-19 among smokers. Conversely, there is no data to quantify the risk of smokers for acquiring the infection with SARS-CoV- ${ }^{22}$. Smoking is characterized by inhalation and by repetitive hand-to-mouth movements, which may increase the chances of viral contamination. Because of this we do not have a convincing explanation for an association between tobacco smoking and lower risk of COVID-19 among PLWH. In our opinion, this result needs replication in other studies, in order to rule out a spurious statistical association because the low number of COVID-19 cases observed. If so, the mechanism by which tobacco smoking might protect against SARS-CoV-2 infection should be investigated.

In this study, no clear association between antiretroviral drugs or combinations and the risk for COVID-19 was found. Previous studies have shown that tenofovir has potent antiviral effect against SARS-CoV-2, because it tightly binds the viral RNA-dependent RNA polymerase 25 . Because of this, clinical trials aimed to assess the efficacy of TDF, a tenofovir salt which reaches higher plasma concentration than TAF, both in the prevention and treatment of COVID-19 were undertaken ${ }^{26}$. Furthermore, in a retrospective study an association between TDF plus FTC treatment and less severity of COVID-19 was found ${ }^{9}$. In our study, only two patients were on TDF plus FTC, because most individuals in this cohort have been switched from TDF to TAF in the last few years. Consequently, we were unable to accurately analyze the effect of TDF on the risk of SARS-CoV-2 infection. In patients on TDF or TAF plus FTC, the incidence of COVID-19 tended to be lower than in those with $A B C$ plus 3TC, which would be in line with a protector effect of tenofovir. However, the incidence among subjects on nucleos(t)ide-free regimen or 3TC based-dual therapy was zero, which would argue against the former hypothesis.

As stated above, the main limitation of this study is the low number of COVID-19 episodes observed among PLWH. This fact prevents us from drawing firm conclusions on factors associated with COVID-19 emergence in this setting, as well as on the precise impact of HIV infection on the outcome of COVID-19, which would require larger sample sizes. However, this study has been conducted in a well-followed cohort, in which clinical data are homogenously collected and serum samples are routinely cryopreserved. Also, COVID-19 diagnosis has been based on PCR and serology, which was carried out in all patients. These are important strengths of this study, which allows a more precise estimation of total and severe COVID-19 incidence among PLWH than that provided by studies based on case reports.

In summary, the incidence of COVID-19 among PLWH in Seville during the first wave of the pandemic was low and similar to that observed in the general population, although the proportion of asymptomatic cases might be lower than in patients without HIV infection. That parameter should be periodically monitored, in order to analyze how it evolves with time and to detect further COVID-19 cases. Future studies with higher number of patients will allow us to more accurately define the role of antiretroviral therapy and tobacco smoking on the incidence and outcome of SARS-CoV-2 infection among PLWH.

\section{References}

1. Centro de Coordinación de Alertas y Emergencias Sanitarias. Ministerio de Sanidad. Actualización nº 158. Enfermedad por el coronavirus (COVID-19). (2020).

https://www.mscbs.gob.es/en/profesionales/saludPublica/ccayes/alertasActual/nCov/documentos/Actualizacion_158_COVID19.pdf

2. Hu, Y., Ma, J., Huang, H. \& Vermund, S. H. Coinfection With HIV and SARS-CoV-2 in Wuhan, China: A 12-Person Case Series. J. Acquir. Immune Defic. Syndr. 85, 1-5 (2020).

3. Gervasoni, C. et al. Clinical Features and Outcomes of Patients With Human Immunodeficiency Virus With COVID-19. Clin. Infect. Dis. (2020). Online ahead of print. doi:10.1093/cid/ciaa579

4. Blanco, J. L. et al. COVID-19 in patients with HIV: clinical case series. Lancet HIV 7, e314-e316 (2020).

5. Vizcarra, P. et al. Description of COVID-19 in HIV-infected individuals: a single-centre, prospective cohort. Lancet HIV 7, e554-e564 (2020).

6. Marimuthu, J., Kumar, B. S. \& Aravind Gandhi, P. HIV and SARS CoV-2 co-infection: A retrospective, record based, case series from South India. J. Med. Virol. (2020). Online ahead of print. doi:10.1002/jmv.26271

7. BHIVA, DAIG, EACS, G. \& P. S. A. S. Statement on risk of COVID-9 for people living with HIV (PLWH). (2020). https://www.eacsociety.org/home/covid-19-and-hiv.html

8. Davies, M.-A. HIV and risk of COVID-19 death: a population cohort study from the Western Cape Province, South Africa. medRxiv Prepr. Serv. Heal. Sci. (2020). Onlind ahead of print. doi:10.1101/2020.07.02.20145185

9. del Amo, J. et al. Incidence and Severity of COVID-19 in HIV-Positive Persons Receiving Antiretroviral Therapy. Ann. Intern. Med. (2020). Online ahead of print. doi:10.7326/m20-3689 
10. Dhama, K. et al. Coronavirus disease 2019-COVID-19. Clin. Microbiol. Rev. 33, 1-48 (2020).

11. European Centre for Disease Prevention and Control. Rapid risk assessment: Coronavirus disease 2019 (COVID-19) pandemic: increased transmission in the EU/EEA and the UK - eighth update. (2020). https://www.ecdc.europa.eu/en/publications-data/rapidrisk-assessment-coronavirus-disease-2019-covid-19-pandemic-eighth-update.

12. Krammer, F. \& Simon, V. Serology assays to manage COVID-19. Science. 368, 1060-1061 (2020).

13. Roche Diagnostic. Elecsys \& Anti-SARS-CoV-2 Immunoassay for the qualitative detection of antibodies against SARS-CoV-2. (2020). https://diagnostics.roche.com/es/es/products/params/elecsys-anti-sars-cov-2.html

14. Vircell. La Solución ELISA como ayuda en el Diagnóstico de COVID-19. (2020). https://www.vircell.com/media/filer_public/0d/78/0d7801d9-b65e-488b-be9b-1a1217face86/covid-19_elisa_es_pms100-0620.pdf.

15. Del Rio, C. COVID-19 in Persons Living with HIV - What Do We Know Today? NEJM J. Watch (2020). Online ahead of print. doi:10.1056/nejm-jw.NA52137

16. Pollán, M. et al. Prevalence of SARS-CoV-2 in Spain (ENE-COVID): a nationwide, population-based seroepidemiological study. Lancet 396, 535-544 (2020).

17. Ministero de Sanidad. Gobierno de España. Estudio ENE-COVID: Informe final estudio nacional de sero-epidemiología de la infección por Sars-CoV-2 en España. (2020). http://www.thelancet.com/journals/lancet/article/PIIS0140-6736.

18. Nikolai, L. A., Meyer, C. G., Kremsner, P. G. \& Velavan, T. P. Asymptomatic SARS Coronavirus 2 infection: Invisible yet invincible. Int. J. Infect. Dis. 100, 112-116 (2020).

19. Long, Q. X. et al. Antibody responses to SARS-CoV-2 in patients with COVID-19. Nat. Med. 26, 845-848 (2020).

20. Gudbjartsson, D. F. et al. Humoral Immune Response to SARS-CoV-2 in Iceland. N. Engl. J. Med. (2020). Online ahead of print. doi:10.1056/nejmoa2026116

21. Maggiolo, F. et al. SARS-CoV-2 infection in persons living with HIV: a single center prospective cohort. J. Med. Virol. (2020). Online ahead of print. doi:10.1002/jmv.26352

22. WHO. Smoking and COVID-19. (2020). https://www.who.int/news-room/commentaries/detail/smoking-and-covid-19.

23. Strzelak, A., Ratajczak, A., Adamiec, A. \& Feleszko, W. Tobacco smoke induces and alters immune responses in the lung triggering inflammation, allergy, asthma and other lung diseases: A mechanistic review. Int. J. Environ. Res. Public Health 15 (5), 1033 (2018).

24. Russo, P. et al. COVID-19 and smoking: Is nicotine the hidden link? Eur. Respir. J. 55(6), 2001116 (2020).

25. Elfiky, A. A. Ribavirin, Remdesivir, Sofosbuvir, Galidesivir, and Tenofovir against SARS-CoV-2 RNA dependent RNA polymerase (RdRp): A molecular docking study. Life Sci. 253, 117592 (2020).

26. Davis, J. S., Ferreira, D., Denholm, J. T. \& Tong, S. Y. Clinical trials for the prevention and treatment of COVID-19: current state of play. Med. J. Aust. 213, 86-93 (2020).

\section{Declarations}

\section{Acknowledgements}

This work was funded in part by the Instituto de Salud Carlos III (Project 'PI16/01443'), integrated in the national I+D+i 2013-2016 and cofunded by the European Union (ERDF/ESF, "Investing in your future"), by the Spanish Network for AIDS investigation (RIS) (www.red.es/redes/inicio) (RD16/0025/0010, RD16/0025/0040), as a part of the Nacional I+ D+I, ISCIII Subdirección General de Evaluación and the European Fund for Development of Regions (FEDER). JAP has received a research extension grant from the Programa de Intensificación de la Actividad de Investigación del Servicio Nacional de Salud Carlos III (I3SNS). FG has received a research extension grant from the Programa de Intensificación de la Actividad de Investigación del Servicio Andaluz de Salud.

\section{Author contributions}

Juan Antonio Pineda (J.A.P.) and Marta FERNANDEZ-FUERTES (M.F.F.); had full access to all the data in the study and takes responsibility for the integrity of the data and the accuracy of the data analysis.

Study concept and design: J.A.P. 
Acquisition, analysis, or interpretation of data: J.A.P.; M.F.F.; Federico GARCIA (F.G.), Ana FUENTES-LOPEZ (A.F.L.), Esther SERRANO-CONDE (E.S.C.) and Elena RODRIGUEZ-PINEDA (E.R.P.)

Statistical analysis: J.A.P.

Drafting of the manuscript: M.F.F. and J.A.P.

Critical revision of the manuscript for important intellectual content: J.A.P., M.F.F., E.R.P., Ana FUENTES-LOPEZ (A.F.L.), Anaïs CORMAGOMEZ (A.C.G.), Pilar RINCON (P.R.), E.S.C., Luis M REAL (L.M.R.), F.G., Juan MACIAS (J.M.)

Obtained funding: J.M., F.G. and J.A.P.

Study supervision: J.A.P.

\section{Competing Interests:}

JM has been an investigator in clinical trials supported by Bristol-Myers Squibb, Gilead and Merck Sharp \& Dome. He has received lectures fees from Gilead, Bristol-Myers Squibb, and Merck Sharp \& Dome, and consulting fees from Bristol Myers-Squibb, Gilead, and Merck Sharp \& Dome. JAP reports having received consulting fees from Bristol-Myers Squibb, Abbvie, ViiV Healthcare, Gilead, Merck Sharp \& Dome, and Janssen Cilag. He has received research support from Bristol-Myers Squibb, ViiV Healthcare, Abbvie, Merck Sharp \& Dome, Janssen Cilag and Gilead and has received lecture fees from Abbvie, Bristol-Myers Squibb, ViiV Healthcare, Merck Sharp \& Dome, Abbvie, Janssen Cilag, and Gilead. FG reports having received consulting fees from Abbvie, ViiV Healthcare, Gilead, Merck Sharp \& Dome, Roche, Hologic \& Qiagen. He has received research support from ViiV Healthcare, Abbvie, and Merck Sharp \& Dome, and has received lecture fees from Abbvie, ViiV Healthcare, Merck Sharp \& Dome, Gilead, Roche, Hologic, Werfen and Intercept. The remaining authors report no conflict of interest.

\section{Tables}

Table 1. Characteristics of the study population $(n=326)$ 


\begin{tabular}{|c|c|}
\hline Parameter & Value \\
\hline Age, years* & $51(42-56)$ \\
\hline Male sex, no (\%) & $269(82)$ \\
\hline \multicolumn{2}{|l|}{ HIV infection way, no (\%) } \\
\hline Drug injection & $123(37)$ \\
\hline Sexual & $181(55)$ \\
\hline Other & $22(7)$ \\
\hline Tobacco smokers, no (\%) & $166(51)$ \\
\hline Daily alcohol intake $\geq 50 \mathrm{~g}$, no (\%) & $29(9)$ \\
\hline Active opiate use & $22(7)$ \\
\hline Baseline CD4 cell counts (cel/uL)* & $660(440-859)$ \\
\hline Plasma HIV-RNA <50 c/mL, no (\%) & $293(90)$ \\
\hline Nadir CD4 cell counts (cel/uL)* & $253(56-399)$ \\
\hline \multicolumn{2}{|l|}{ ART combination } \\
\hline TAF or TDF/FTC-based & $160(49)$ \\
\hline ABC/3TC-based & $70(21)$ \\
\hline 3TC-including dual therapy & $42(13)$ \\
\hline Nucleos(t)ide-free & $54(17)$ \\
\hline CDC clinical category C, n (\%) & $88(27)$ \\
\hline Active HBV infection & $4(1.2)$ \\
\hline Positive plasma anti-HCV & $140(43)$ \\
\hline Active HCV infection & $1(0.3)$ \\
\hline \multicolumn{2}{|l|}{ Charlson index, n (\%) } \\
\hline 0 & $89(27)$ \\
\hline $1-2$ & $148(45)$ \\
\hline $3-5$ & $64(20)$ \\
\hline$\geq 5$ & $25(8)$ \\
\hline
\end{tabular}

*Median (Q1-Q3)

Abbreviations: ART: Antiretroviral Therapy; TAF: Tenofovir Alafenamide; TDF: Tenofovir Diphosphate; FTC: Emtricitabine; ABC: Abacavir; 3TC: Lamivudine; HBV: Hepatitis B Virus; HCV: Hepatitis C Virus.

Table 2. Clinical and demographic data of patients who developed COVID-19. 


\begin{tabular}{|c|c|c|c|c|c|c|c|c|c|c|}
\hline Patient & Sex & $\begin{array}{l}\text { Age } \\
\text { (years) }\end{array}$ & $\begin{array}{l}\text { Tobacco } \\
\text { smoker }\end{array}$ & $\begin{array}{l}\text { Baseline } \\
\text { CD4+ } \\
\text { count/ } \\
\mu L\end{array}$ & $\begin{array}{l}\text { Plasma } \\
\text { HIV- } \\
\text { RNA } \\
\text { c/mL }\end{array}$ & $\begin{array}{l}\text { Antiretroviral } \\
\text { therapy }\end{array}$ & $\begin{array}{l}\text { CDC } \\
\text { stage }\end{array}$ & $\begin{array}{l}\text { Charlson } \\
\text { index }\end{array}$ & $\begin{array}{l}\text { SARS-CoV-2 } \\
\text { RNA in } \\
\text { nasopharynx } \\
\text { exudate }\end{array}$ & $\begin{array}{l}\text { Clinical } \\
\text { presentation }\end{array}$ \\
\hline 1 & Female & 69 & No & 739 & $<50$ & $\begin{array}{l}\text { TAF/FTC/DRV- } \\
\mathrm{c}\end{array}$ & B & 3 & Positive & $\begin{array}{l}\text { Pneumonia. } \\
\text { Respiratory } \\
\text { Failure. } \\
\text { Death. }\end{array}$ \\
\hline 2 & Male & 34 & No & 247 & $<50$ & ABC/3TC/DTG & B & 0 & Not tested & $\begin{array}{l}\text { Fever. Mild } \\
\text { respiratory } \\
\text { symptoms. }\end{array}$ \\
\hline 3 & Male & 37 & No & 948 & $<50$ & ABC/3TC/DTG & B & 0 & Not tested & $\begin{array}{l}\text { Fever. Mild } \\
\text { respiratory } \\
\text { symptoms. }\end{array}$ \\
\hline 4 & Male & 53 & No & 712 & $<50$ & ABC/3TC/DTG & B & 2 & Positive & $\begin{array}{l}\text { Fever. Mild } \\
\text { respiratory } \\
\text { symptoms. }\end{array}$ \\
\hline
\end{tabular}

Abbreviations: TAF: Tenofovir Alafenamide; FTC: Emtricitabine; DRV-c: Cobicistat-boosted Darunavir ABC: Abacavir; 3TC: Lamivudine; DTG: Dolutegravir 